\title{
Cognitive management strategies in knowledge society: specific character and potential
}

\author{
Anna A. Kornienko ${ }^{1, a}$ \\ ${ }^{1}$ Tomsk Polytechnic University, 634050 Lenin Avenue, 30, Tomsk, Russia
}

\begin{abstract}
The article analyzes the process of formation of cognitive management strategies in knowledge society. The specific character of these strategies is identified, its potential is characterized. The article touches upon the issue of meaning of management through knowledge arrays as a relevant impact resource. We outline the idea that the problem of inevitable knowledge obsolescence can find its effective solution through addressing to the mechanisms of innovative development. In social systems by virtue of the ability of innovation to generate the opportunity to adapt to a situation, where environment has a high level of dynamics and risks complexity, in knowledge society the ideas of innovation manifest themselves in all social spheres. It is proved that evaluation of the role of innovation, proposed in the problem field of cognitive management, creates preconditions for relevant assessment of knowledge as a dominant factor of social development and dominant values of knowledge society, as well as gives an opportunity to evaluate adequately the status of knowledge in value increasing of individual intellectual potential.
\end{abstract}

\section{Introduction}

The term «strategy» is actively used in modern philosophy of management; this is connected with the ability of appropriate and adequate influence, which is necessary for the management process. This type of influence provides for prospect object development. The choice of the management strategy should be wellresourced in order to make management influence more effective. In knowledge society the resources are presented by knowledge.

Transformation of the knowledge status into knowledge civilization leads to a change in management strategies. It is important to start with the role of innovations in knowledge society, introduced in enterprises, social institutions and communities of knowledge society. By definition, knowledge society «is an educating, rapidly developing society, based on reproduction and spread of knowledge». At the same time the process of new knowledge emergence is accelerated along with a social interest growth towards new knowledge and knowledge consumption speed.

The high rate of obsolescence of knowledge becomes the main problem. Therefore, «culture of knowledge society is based not only on the principles of permanence and reproduction, but on the principles of creativity and updating» [1].

Bringing up an issue of strategy specifics of innovation problem investigation in the context of the

\footnotetext{
a Corresponding author: anna_kornienko@mail.ru
}

knowledge society concept, it is worth paying attention to socio-cultural effects of the phenomenon of innovation. The sense of this effect, which in our opinion is manifested only in knowledge society, consists of the diffusion, to which innovations in knowledge civilization are exposed. Diffusion takes place within certain areas as well as it touches complex interdisciplinary interactions, which causes synergy of subject areas. The sociocultural effect is also consists of innovation ability to initiate transformations of knowledge, which cause reformations of social structures and processes.

\section{Materials and methods}

The solution of the problem required a necessary use of general scientific and philosophical principles and methods, such as a dialectical method, a systematic approach, a cognitive analytical method, a principle of determinism, a principle of development, applied in the context, and due regard should be paid to the specifics reasoned by transition to knowledge civilization.

\section{Results and discussion}

What is innovation as a factor of social development? The first attempts to answer this question were made by economists, who referred to the potential of N.D. Kondratiev's cycles theory. This theory allowed making 
a distinction between such phenomena as «innovation» and «novelty». N.D. Kondratiev also described the role of grand-scale inventions as a prerequisite for industrial revolution; also in his work «The main problems of economic statics and dynamics» he justified the thesis about the social effects of economic cycle dynamics and proved the idea of economic cycles depending on the dynamics of large-scale technical inventions.

J. Schumpeter, referring to the issue of economic cycle sources, defined innovation as a tool used in a period of economic depression in order to update and change production. It was J. Schumpeter who classified innovations of the economic science in his work «History of Economic Analysis» and introduced the theory of «Innovation Packet».

J. Schumpeter noticed that the change of the economic cycle phase is basically a transformation of production under the influence of radical technological innovation. Moreover new commercial enterprises, new commodities, the process of money accumulation - they are all preceded by technical innovations.

J. Schumpeter identified and analyzed wavy cycles, based on an appeal to possibilities of a steam engine (1792-1842), railway vehicles (1843-1897), electricity and road transport (1898-1949). Innovation processes are presented by J. Schumpeter as a potential capacity to overcome an economic decline and make a transition to a new cycle of development, a new phase of economic recovery. G. Mensch identified a number of «peaks» of innovation activity, they are: 1764, 1825, 1886 and 1935. G. Mensch also made a forecast, according to which the next burst of innovation activity took place in 1995 when scientists succeeded in genetic engineering, when unknown energy resources were revealed, and, finally, which is very important for us as we are trying to consider the issue of innovation in the context of becoming knowledge society. G. Mensch associated the burst of innovation activity of 1995 with the success of microprocessor technology.

A little later, in the $90 \mathrm{~s}$ of the twentieth century, Boris Santo, identifying characteristics of modern economy and common patterns of the innovation process, entitled the progress of science as the most powerful factor of the economic progress. Among the specific features of the innovation process B. Santo distinguished cyclicity, separation of functional organizational units, systematicity and increase of economic and scientific-technical potential (premises for technological renovation of production).

According to B. Santo, innovative economy chooses science as a new basis. We believe that although it is an economic approach to traditions that should be seen as the basis for interpretation of innovation as the dominant value of knowledge society, the economic approach is not wide enough to interpret a full range of manifestations and consequences of innovation processes in the context of knowledge civilization.

Y.A. Nikitina finds innovation studies as a «universal science of creative renewal» by virtue of the fact that all manifestations of reality are illustrated not only by apparition and spread of something new, but also by qualitative renewal of the entire scope of innovation. [2].

So, within the bounds of the economic approach, the subjective creative role of human as an agent of the social change, creating new ideas and implementing innovations, is scarcely analyzed. This is especially important for interpretation of the phenomenon of innovation, evolving in line with the concept of knowledge society.

We believe that this approach to innovation, formed within the boundaries of cognitive management allow us to evaluate adequately the status of knowledge as the dominant factor of social development and basic values of knowledge society, and finally, to evaluate the role of knowledge in value increase of the intellectual potential of an individual.

Creative management activity serves as a platform for social innovation in knowledge society. Today we can talk about the methods of creative thinking stimulation. Among these methods along with the chaotization of the consciousness status and thinking in order to overcome stereotypes of thinking, there is training of perceptive thinking, E.N. Knyazeva proposed a method of divergent thinking training as a method of creative knowledge and action.

«While convergent thinking - E.N. Knyazeva wrote comes from the initially stated problem through a series of prescribed transactions to the one correct solution. Divergent thinking allows conducting research in different directions, other from the original task, in order to advance a number of possible ideas and their combinations, which could serve as a solution to a problem and form the basis for constructive action» [3]. The author wrote about the need for management actions to be embedded in environment, about interactive activities as a condition of management actions effectiveness.

This embeddedness in environment means the ability to contextualize, which is used in knowledge management: «To think and to act interactively and make a management impact in compliance with the current situation mean to understand the ambiguity and the relative unpredictability of a resulting response of environment, of enterprise, at which an action is directed. Besides, contextualization means to be aware of complexity and non-linearity of establishing feedbacks, to allow a certain percentage of the chaos of internal mobility and flexibility in the emerging system of interactive relationships and to be able to use the rules of resonance embedded in environment to form a steadily evolving unified whole» [3].

We noted above that the option of the management impact strategy may be highly effective in case if an option is well-resourced. That resource in knowledge society is presented by knowledge, which gained the status of a source of development in the social and cultural sphere. The last circumstance explains the 
possibility of appealing to the potential of cognitive management strategies in knowledge society.

A society, in which the dominant resource is knowledge, forms an innovative management strategy. This strategy is represented by cognitive management, which plays the role of a new management theory in knowledge society. The term «knowledge management» was originated in the late twentieth century - it was introduced by Carl Wing in 1986. The attention to this issue is reasoned by the fact that today globalization, development of technologies and competition intensification reduce the role of material resources. Of course, land, labor and capital continue to be significant. However, to ensure competitiveness, knowledge ranks a leading position: the winner is the one who knows best how to use the material resources. Knowledge turned into a resource in terms of economy and sense.

Knowledge is a specific resource that has a specific dynamics of formation and requires special management actions. The authors of the monograph under the title «Knowledge Management» believe that knowledge management is an interdisciplinary approach to achieve a system of objectives through the most effective use of knowledge. Knowledge management allows us to find the necessary knowledge, to acquire this knowledge and to apply them in implementation of the society strategy. Knowledge management in knowledge society acquires the status of an ideology; it penetrates in all social spheres.

In science, a number of terms, including the term «knowledge» in the attributive position, have appeared: knowledge assets, knowledge resources, knowledge economy, knowledge work, a knowledge worker, knowledge-based theory of the firm, a knowledgeintensive firm, knowledge sharing, knowledge exploration/exploitation. Such issues as a spiral model of knowledge creation (I. Nonaka), mechanisms which provide the transfer of knowledge (L.Argote, P.Ingram), the process of creating structures (D.A. Garvin), the role of knowledge in forgetting management (P. de Holan, N. Phillips, T. Lawrence) are actively discussed. Besides, such problems as diagnosis of cultural barriers in knowledge management (D.W. Delong, L.Fahey), the models used to measure intellectual capital (N. Bontis), the human factor in knowledge management (J. Barling ), the role of knowledge in the dynamics of growth (P.M. Romer) are also under consideration.

Problems of cognitive management require a clear distinction of concepts such as data, information and knowledge. Through this distinction, D.W. Delong and L. Fahey, solving the problem of cultural barriers diagnosis in knowledge management, see the specifics of this distinction in the following. Data, according to the authors, are an unconverted or unabridged description of past, present and future events; information is interpreted as models detected in data. Knowledge is interpreted as a resource that is dependent on the context and concluded in the current practice [4].
Embodied in a language, knowledge plays the role of a decision-making and action-making factor. It is necessary to take into account the distinction between explicit knowledge (encoded and reflected in formal rules, tools, processes) and tacit knowledge (this is what we know, but we cannot explain). Tacit knowledge, according to the researchers (I. Nonaka), is highly personal knowledge; this knowledge is nonformalized and hardly explainable («we know more than we can tell» - M. Polani). Often tacit knowledge is presented by technical skills. The last one is a non-formal type of hardly explainable and expressible knowledge («knowhow"). This knowledge is in fact of a special cognitive dimension, based on the insight, intuition, anticipation, and it is rooted in ideals, values and emotions.

Tacit knowledge is of two levels - technical (nonformalized knowledge and skills, «know-how»), and cognitive (representation, ideals, values, mental models) $[5,6]$. And the process of knowledge creation extension of knowledge - is the interaction of explicit and tacit knowledge, which has a spiral form. The authors propose a model of such interaction, called SECI. SECI is a derivation of the terms socialization, externalization, combination, internalization.

D.W. Delong and L. Fahey, speaking about the role of knowledge in the knowledge management processes, name such types of knowledge as:

- Human knowledge is individual knowledge, which manifests itself in skills and professional competencies combining tacit and explicit knowledge;

- Social knowledge, which exists in relations between individuals or within groups. Social knowledge is mostly tacit; it belongs to the group members and develops only in the process of collaborative work. This type of knowledge determines the ability of individuals to collaborate effectively;

- Structured knowledge, which is embodied in systems, processes, tools and practices. Knowledge in this case is explicit and based on rules. The main difference between the structured knowledge and the first two types of knowledge is that the structured knowledge is considered to exist regardless of people who hold knowledge. This type of knowledge is the most important resource [4].

Cognitive management, as a new strategy in the management of knowledge society, is based on two principles: knowledge management and management by means of knowledge resources. Cognitive management as a new management paradigm in the knowledge society will show its effectiveness to a greater extent and degree if the knowledge management strategy will be developed with the help of knowledge. What is the strategy? In 1971 K.R. Andrews published a book «The concept of corporate strategy», in which the author used the approach to a strategy (SWOT-analysis) as to the art of leadership; the basis of this art is the analysis of strengths, weaknesses, opportunities and threats.

Conducting SWOT-analysis requires knowledge of internal capabilities of an object (e.g. an enterprise), its 
strengths, weaknesses, opportunities and threats of competitive environment. The strategy is focused on actions that contribute to the stability of an object, to avoidance of threats and to the usage of potential of an object. M. Zack proposed to consider a strategy as a balance between external environment (and its potential threats) and the internal potential of a managed object [7].

In addition to the SWOT-strategy, there is also a strategic model of «five forces» introduced by M. Porter. This strategy puts emphasis on factors, which contribute to the emergence of opportunities and threats. And, besides, there is a resource strategy. An object of this strategy is strategically positioned, and the initial point of this position is a resource. Hence, the effectiveness of the chosen strategy is determined by the resource basis of an object.

Thus the resource base for knowledge society is knowledge, which is called a strategic resource of knowledge society, by virtue of the fact that these intellectual resources, when accumulating, allow maintaining a competitive advantage. What allows knowledge to ensure the sustainability of these benefits? According to M. Zack, knowledge, especially the knowledge depending on the context, tacit knowledge embodied in complex organizational processes and gained as a result of experience is usually unique - they are difficult to imitate. Unlike many traditional resources, they cannot be bought on the market in a ready-to-use form. In order to gain such knowledge, competitors should gain the same experience. However, the acquisition of knowledge through experience takes time and competitors cannot speed up the process of learning just through investment increasing [7].

A huge role in providing sustainability plays the ability of knowledge synergy, knowledge organization through a synergistic integration, that is, for example, the ability of knowledge obtained by an expert method of future risks to integrate with existing "meta-knowledge", creating a synergy of knowledge. It involves the phenomenon of «increasing returns» (P. Romer), the meaning of which is in increasing knowledge return according to the degree of its use, and this, according to P. Romer, creates a self-reinforcing cycle. In this respect, strategically significant areas of knowledge integrate cognitive experience inherent to these areas into «critical teaching mass», using arrays of knowledge in response to the strategic challenges of our time [8].

In general, the knowledge strategy characterizes the approach of knowledge resources adjustment in accordance with the intellectual requirements of the strategy. According to M. Zack [9], the knowledge strategy can be described in various ways. For example, by pointing out the extent to which an object (for example, an enterprise) generates knowledge, in addition, evaluating the source of knowledge (internal, external).

The use of the term «knowledge strategy» requires clarification through the correlation of this category to the category of the «knowledge management strategy»these two concepts are multi-ordinal. The knowledge strategy is based on knowledge, it is the competitive strategy, and it is based on cognitive resources. The knowledge strategy is focused on understanding which knowledge and why is strategic, while the knowledge management strategy navigates and determines processes and infrastructure (organizational and technological) in order to manage knowledge [9]. The author distinguishes different types of knowledge management, for example, strategic knowledge management, operational knowledge management (routine activities and processes). If in the course of strategic knowledge management the problem of information provision for strategic decision-making is solved, then during the process of operational knowledge management the implementation of the strategy is performed to the full extent.

Knowledge Management (the term was introduced in the early 90-s of the XX century) is a set of processes, focused on development and effective management of knowledge. Speaking about the knowledge management process it should be taken into account that this process includes also professional intelligence management, it is particularly important in the post-industrial economy. The morphology of the professional intelligence includes such blocks as cognitive knowledge (a basic level of a discipline), advanced skills («how», know-how), systemic understanding («why», know-why), selfmotivated creativity («why" care-why). And if the first three blocks in the morphology of the professional intelligence are reflected in systems, databases, and operating technologies, the last block of crucial components of knowledge as a professional intelligence, according J. Quinn, P. Anderson, S. Finkelstein [10] is reflected in corporate culture.

The choice of the management influence strategy demonstrates its maximal efficiency only in a situation when this choice is well-resourced. In knowledge civilization this resource is knowledge. In knowledge society it has acquired the status of a source of the social and cultural sphere development, which generates the need for addressing to the possibilities of cognitive management strategies - the last strategies innovative in their nature and mechanisms. This strategy is presented by cognitive management.

The authors tried to prove the idea that knowledge, turned into a resource in an economic sense, is a specific resource. This resource, having a special dynamic form, requires specific management actions and mechanisms. Implementation of knowledge strategies in knowledge arrays management is possible only from a position of an interdisciplinary approach. It allows achieving the objectives system through the effective use of knowledge. Knowledge management itself in knowledge society is transformed into an ideology. A special categorical apparatus is formulated, in which the term «knowledge» used as an attribute - knowledge assets, knowledge worker, knowledge resources, knowledge sharing, etc. 
The authors believe that the analysis of nature, specifics and potential of cognitive management strategies is the theoretical platform based on which it is possible to analyze a number of important issues related to knowledge management. This is analysis of models of knowledge creation, teaching structures creation, knowledge transfer mechanisms and mechanisms of forgetting. This is a study of cultural barriers in knowledge management, the research of intellectual capital evaluation models, and finally, the analysis of the knowledge role in growth dynamics and everything, associated with knowledge as the most important resource factor in knowledge society.

\section{References}

1. F. Janszen, The age of Innovation (London: Prentice Hall, 2000)

2. Y.A. Nikitina, Bulletin of Buryat State University, 6, 101-104 (2009)

3. E.N. Knyazeva, S.P. Kurdumov Synergy basis (SPb.: Aleteya, 2002)

4. D.W. DeLong, L. Fahey, Academy of Management Executive, 14 (4), 437-457 (2000)

5. I. Nonaka, Harvard Business review, NovemberDecember, 96-105 (1991)

6. I. Nonaka, N. Konno, California management review, 40 (3), (1998)

7. M.H. Zack, California Management Review, 41 (3), 125-145 (1999)

8. P.M. Romer, Strategy+business, November 20, (2001)

9. M.H. Zack, Developing a Knowledge strategy: Epilogue. In: N.Bontis, Choo C.W. (eds.). The Strategic Management of Intellectual Capital and Organizational Knowledge: A collection of readings (2002)

10. J.B. Quinn, P. Anderson, S. Finkelstein, Harvard Business Review, March-April, 71-81 (1996) 